\title{
Effectiveness of a Novel Low Cost Intervention to Reduce Prenatal Alcohol Exposure in the Congo
}

\author{
Andrew D. Williams'1, Yannick Nkombo², Gery Nkodia², Gary Leonardson ${ }^{3}$, \\ Kathryn Martsolf ${ }^{1}$, Larry Burd ${ }^{1}$ \\ ${ }^{1}$ North Dakota Fetal Alcohol Syndrome Center, University of North Dakota School of Medicine and Health \\ Sciences, Grand Forks, USA \\ ${ }^{2}$ Congolese Association for Research and Prevention of Fetal Alcohol Spectrum Disorders, Brazzaville, Congo \\ ${ }^{3}$ Mountain Plains Research, Dillon, USA \\ Email: larry.burd@med.und.edu
}

Received 23 January 2014; revised 20 February 2014; accepted 27 February 2014

Copyright (C) 2014 by authors and Scientific Research Publishing Inc.

This work is licensed under the Creative Commons Attribution International License (CC BY). http://creativecommons.org/licenses/by/4.0/

(c) () Open Access

\begin{abstract}
Objective: Determine the effectiveness of an intervention to reduce prenatal alcohol exposure in the Congo. Methods: We utilized a screening tool validated in the Congo to identify women who were drinking during pregnancy. The intervention was implemented by prenatal care providers comparing 162 women receiving the intervention with 58 (controls) who did not. The study endpoints were proportion of women who quit drinking, drinking days per week, drinks per drinking day, most drinks on any day, and number of binge episodes per week. Results: In the control group $36 \%$ of the women quit drinking compared to $54 \%$ in the intervention group (Chi-square $5.61 ; p=$ 0.02). The number of drinking days per week for the controls decreased by $50.1 \%$ compared to $68 \%$ for the intervention group $(p=0.008)$; drinks per drinking day for the controls decreased by $37 \%$ compared to $60.1 \%$ for the intervention group $(p=0.001)$; and most drinks on any occasion in the controls decreased by $38 \%$ compared to $61 \%$ for the intervention group $(p=0.004)$. Conclusions: This study demonstrates the effectiveness of a low cost in-office intervention to reduce prenatal alcohol exposure in the Congo. At $\mathbf{\$ 1 . 5 0}$ per beer, the reduction in drinks per week would more than pay for the cost of the intervention. In addition to efforts to reduce alcohol use prior to pregnancy in the Congo, providers can now offer an evidence based intervention to reduce exposure for women who continue to drink during pregnancy.
\end{abstract}

\section{Keywords}

Women; Prenatal; Alcohol; Exposure; Intervention; Treatment; Congo; Binge Episodes 


\section{Introduction}

Alcohol use is a major contributor to global burden of disease accounting for $4 \%$ of total world-wide mortality and between 4 and 5\% of all disability adjusted life years [1]. Among women 1.1\% of total global mortality and $1.4 \%$ of global disability-adjusted life years were attributable to alcohol use in 2009 [2]. Alcohol and tobacco use may now account for nearly equivalent proportions of disability-adjusted life years world-wide [3]. However, it is possible that this represents an underestimate of the impact of alcohol use in the developing world, especially Africa, since the data from this region are often incomplete [2].

In Uganda 36\% of women report current alcohol use and $10.7 \%$ meet criteria for problem drinkers [4]. In Nigeria $14 \%$ are current drinkers and $8.9 \%$ are problem drinkers [4]. Most of these women are of child bearing age. In many countries prenatal alcohol exposure (PAE) has also been found to be a risk marker for increased maternal mortality, fetal mortality, infant and child mortality, preterm birth and morbidity [5]-[10].

South Africa which has the highest reported rates of PAE and binge drinking in Africa, also has some of the world's highest rates of fetal alcohol spectrum disorders [11] [12]. Table 1 provides a summary of published studies of PAE and binge drinking from Sub-Saharan Africa. Available data on PAE from Africa vary eight-fold from 5.1\% in Ethiopia to over 40\% in Zimbabwe [13] [14].

The Republic of the Congo has an annual per capita health expenditure of \$108, which ranks 145th worldwide for per capita health expenditures [15] [16]. In Congo one in six infants (16.7\%) are born prematurely, which is the second highest rate in the world and the maternal mortality ratio is the $19^{\text {th }}$ highest rate in the world at 580 per 100,000 [17] [18]. The infant mortality rate is 74.2/1000 live births which is the 17th highest in the world [19].

Recent data on PAE in the Congo are alarming. Among pregnant women, 23\% reported drinking during pregnancy and 87\% of them also reported binge drinking in 2012 [20]. Among women who were drinking during pregnancy 83\% continued to drink after recognition of pregnancy [20]. Only one-in-six women (16.7\%) quit drinking after recognition of pregnancy. Continued drinking after recognition of pregnancy indicates that PAE likely occurs over all three trimesters of pregnancy for nearly 1 in every 5 pregnancies in Congo. Prenatal smoking increases duration and magnitude of exposure [21]. As a result there is a widespread concern about the adverse effects of alcohol during pregnancy and the lack of affordable evidence based intervention programs for use in the Congo.

Prior to this project, there had been no known published reports of prevention or intervention programs to reduce PAE in prenatal care settings in the Congo. The medical community expressed concerns to us about the rates of PAE especially in Brazzaville, but had not carried out formal research. This study is a component of a collaborative response to concerns expressed by the prenatal care providers and community members from the Congo. The community goal was to develop and evaluate a very low cost in-office intervention to reduce alcohol use for women who were still drinking at the time of their prenatal care visit.

Table 1. Summary of the published research from Sub-Saharan Africa on prenatal alcohol exposure (modified from Williams et al., 2013).

\begin{tabular}{|c|c|c|c|c|c|c|c|}
\hline & \multirow{2}{*}{ Total } & \multicolumn{2}{|c|}{$\begin{array}{l}\text { Number/Percent } \\
\text { Reporting Drinking }\end{array}$} & \multicolumn{2}{|c|}{$\begin{array}{c}\text { Number/Percent also } \\
\text { Reporting Bingeing }\end{array}$} & \multirow{2}{*}{ Population Studied } & \multirow{2}{*}{ Screening Tool } \\
\hline & & $\mathrm{N}$ & $\%$ & $\mathrm{~N}$ & $\%$ & & \\
\hline $\begin{array}{l}\text { Uganda } \\
\text { [22] }\end{array}$ & 610 & 180 & 29.5 & 56 & 31 & Urban; National referral hospital & Clinic interview; CAGE \\
\hline $\begin{array}{l}\text { D.R. Congo } \\
{[23]}\end{array}$ & 240 & 78 & 32.5 & 61 & 78 & Urban; Antenatal Clinics & Clinic interview \\
\hline $\begin{array}{l}\text { Ethiopia } \\
\text { [14] }\end{array}$ & 1065 & 54 & 5.1 & & & $\begin{array}{l}\text { Urban/ Rural Mix; } \\
\text { Data Surveillance Site }\end{array}$ & Interview \\
\hline $\begin{array}{c}\text { Zimbabwe } \\
\text { [13] }\end{array}$ & 80 & 39 & 48.8 & & & & \\
\hline $\begin{array}{c}\text { South Africa } \\
{[11]}\end{array}$ & 636 & 272 & 42.8 & 150 & 55 & Urban/Rural Mix; Prenatal Clinics & $\begin{array}{l}\text { Clinic } \\
\text { Interview }\end{array}$ \\
\hline $\begin{array}{c}\text { Congo } \\
\text { [20] }\end{array}$ & 3099 & 715 & 23.0 & 625 & 87.1 & Urban women in prenatal clinic & $\begin{array}{c}\text { Systematic screening } \\
1 \text { Question Screen }\end{array}$ \\
\hline
\end{tabular}




\section{Methods}

Data collection was completed at 10 prenatal care sites in Brazzaville by local prenatal care staff. The city of Brazzaville has 50,000 live births annually [24]. The prenatal care sites in Brazzaville were selected to be approximately representative of women attending prenatal care in the city. We did not sample women from rural areas of the Congo.

We obtained approval for the study from the University of North Dakota Institutional Review Board, and the Ministry of Health in Brazzaville. This project is a cooperative effort between the Congolese Association for Research and Prevention of Fetal Alcohol Spectrum Disorders (SAF Congo) and the University of North Dakota Fetal Alcohol Syndrome Center. The consent forms were in French and each consenting woman received a copy of the form.

Training and screening materials were developed collaboratively by the North Dakota and Brazzaville teams and translated into French. The SAF Congo staff then utilized these materials for project training prior to data collection. Ongoing consultation via a phone-based training was provided during the data collection period. Each pregnant woman was interviewed in French or a local language. At the most recent prenatal care visit we utilized the 1-Question screen (When was your last drink?) to identify women who were drinking during pregnancy [20] [25] [26]. The 1-Question screen has been validated in prenatal care clinics in the Congo [20].

We also collected data for the variables: duration of gestational exposure (estimated week of gestation at the time of the visit), key maternal factors (maternal weight, maternal age), current exposure status ("When was your last drink?”), frequency (drinking days per week) and quantity (usual drinks per drinking day and maximum number of drinks on any one occasion during this pregnancy). The number of drinks was calculated based on self-reported drinks (usually bottled beer). We then set up a follow-up visit at a later prenatal care visit to collect data on the exposure variables (after the intervention or a comparable time period for the observe-only group). At the second assessment we also collected data on quit rates (the proportion of women who quit drinking by group). The intervention group was comprised of 162 women. The intervention arm was completed first and then the comparison group was enrolled and assessed twice and at equivalent time intervals between first screening and the second assessment. The control group (controls) was comprised of 58 women who were enrolled about 4 months after the intervention group was finished. The same variables and procedures were used to collect exposure data. The controls did not receive the intervention and were followed to determine the natural history of drinking (frequency and quantity) in the Congo. In both arms consecutive women were offered the screening. Study participants were not selected for screening in any other way. When reporting on alcohol use participants were asked to report on current use. The project was conducted in 2012 and 2013.

The sites screened 220 urban women with the 1-Question screening. For the controls the initial visit was at 22.41 gestational weeks ( $\mathrm{sd}=3.84$ ) and for the intervention group, at 24.28 weeks ( $\mathrm{sd}=5.13$ ). For the controls the second assessment was at 29.48 gestational weeks ( $\mathrm{sd}=3.92$ ) 7.07 weeks later compared with the intervention group $30.40(\mathrm{sd}=4.94) 6.12$ weeks later. The intervention group was slightly further along in the pregnancy compared to the controls.

In Brazzaville, the screeners who are local residents indicated that the typical drink is beer usually 50 - 70 centiliters (16 - 24 ounces) with an alcohol content of about 5\%. Each beer has between 18 and 28 grams of alcohol or an average of 23 grams of alcohol per drink. Thus, a typical drink in the Congo is equivalent to approximately 1.6 standard drinks (if 14 grams of alcohol comprise a standard drink) [27]. We did not collect data to allow for calculation of standard drinks using a specified number of grams of alcohol as the unit of delineation.

\subsection{The Intervention}

The content and format of the intervention format was developed in collaboration with the Congo partners. The goal was to develop an intervention that: was easy to implement in the prenatal care setting; was low cost; did not require extensive staff or resources to implement; and could be provided in multiple prenatal care settings.

The final intervention was a 6 panel poster with the content delivered by the prenatal care provider in the office (Figure 1). The goal was to provide the intervention in 10 minutes or less. The pictorial intervention approach was developed for the Congo to provide a method of presentation of standardized content that emphasized a mix of verbal and pictorial content. The art was developed by the Congo research staff to maximize cultural appropriateness. 


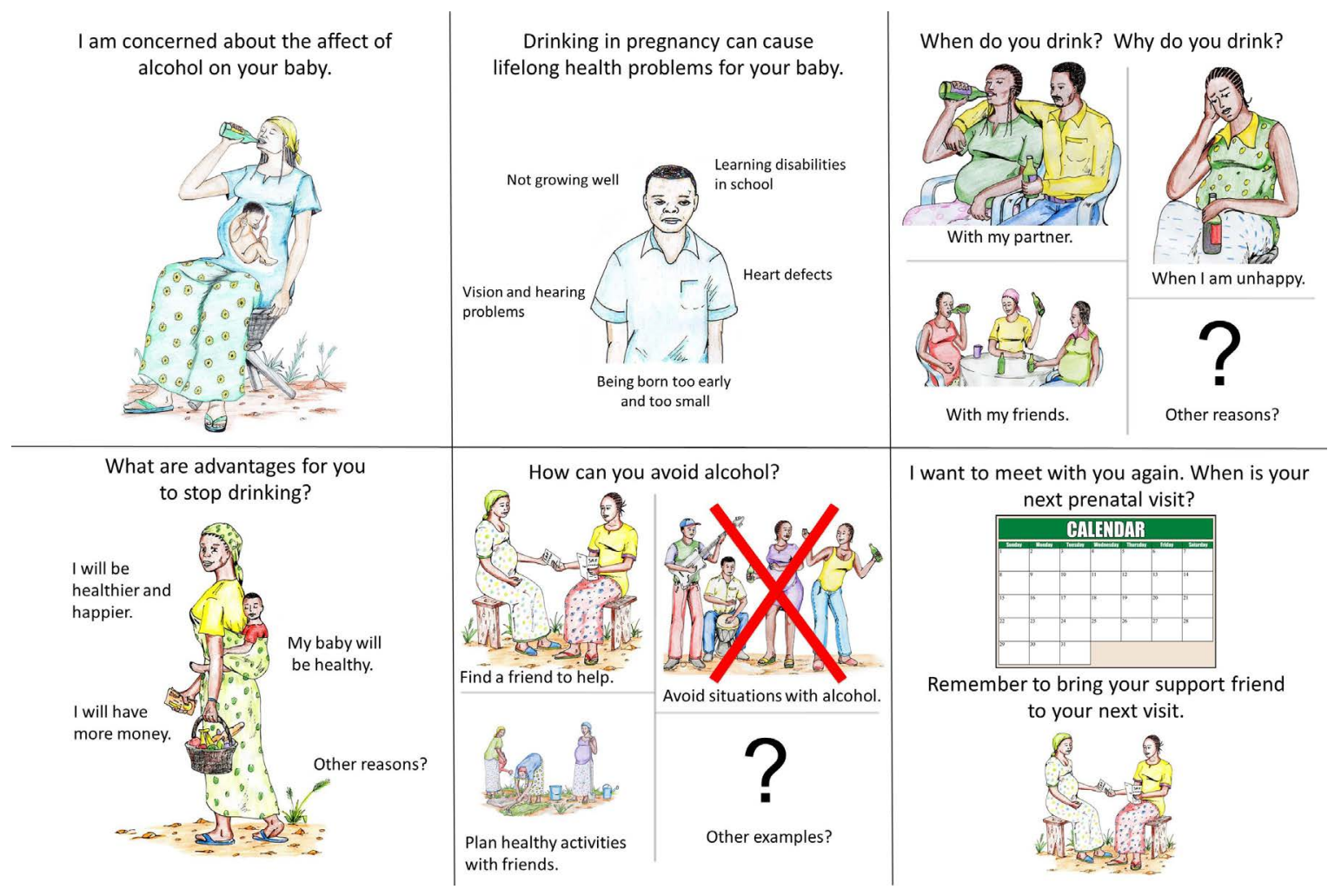

Figure 1. The six panel pictorial intervention utilized in the study.

\subsection{Statistical Analysis}

Analysis of variance (ANOVA) was used to examine the initial pre-test differences (before intervention) in means of continuous dependent variable measures (number of days person drinks per week, number of drinks on average per day when drinking, average number of binges, most drinks at any one time, age, weight, and week of pregnancy) and the independent categorical measures (controls and intervention).

Analysis of Covariance (ANCOVA) was used to examine the differences in means of continuous dependent variable measures (average drinks per drinking day, average binge episodes in pregnancy, most drinks at once in pregnancy, drinking days for week, and amount of drink) and the independent categorical measures risk factors (e.g., controls, intervention) after controlling for the effects of covariates (weight, week of pregnancy, pre- intervention measures).

We used the chi-square test $\left[\chi^{2}\right]$ to compare differences in categorical factors (e.g. risk rating, and type of alcoholic drink) in the controls and intervention group. Statistical significance (alpha level) was set at .05 for all analyses.

The data for each subject were reviewed for errors. Any out of range values were then reconciled by email or phone with the prenatal care chart. Each woman was provided a SAF Congo promotional bracelet for participation.

\section{Results}

From 10 prenatal care sites in Brazzaville, 220 women completed the screening and had complete data. The intervention group was comprised of 162 women and the control group of 58 women. The mean maternal weight was significantly different between groups, about 4.4 four kilos $(\mathrm{p}<0.003)$ (Table 2). The gestational week also differed between the groups with the intervention group 1.8 weeks further along in their pregnancy (Table 2).

In Table 3, the exposure data comparisons by group are presented. Only two variables were significantly different between groups. The controls had a higher value for most drinks on a drinking day 4.3 vs 3.8; $\mathrm{p}<0.015$, and the most drinks on an occasion 7.9 vs 7.1; $\mathrm{p}<0.012$ (Table 3). We also found between group differences on 
Table 2. Demographic factors for the 220 study participants.

\begin{tabular}{cccc}
\hline Factor & Intervention $[\mathrm{n}=162]$ & Controls $[\mathrm{n}=58]$ & Probability \\
\hline & Mean $=25.85$ & Mean $=24.76$ & 0.123 \\
Weight $[\mathrm{kg}]$ & $\mathrm{SD}=4.84$ & $\mathrm{SD}=3.90$ & 0.003 \\
& Mean $=62.04$ & Mean $=66.44$ & \\
Week of Pregnancy & $\mathrm{SD}=9.38$ & $\mathrm{SD}=10.48$ & 0.012 \\
& $\mathrm{Mean}=24.28$ & $\mathrm{Mean}=22.41$ & $\mathrm{SD}=3.84$ \\
\hline
\end{tabular}

Statistical Procedure $=$ ANOVA.

Table 3. Exposure variables for the study participants by group at baseline.

\begin{tabular}{cccc} 
Factor & Intervention $[\mathrm{n}=162]$ & Controls $[\mathrm{n}=58]$ & Probability \\
\hline \multirow{2}{*}{ Number of Days Person Drinks per Week } & Mean $=2.72$ & Mean $=2.79$ & 0.687 \\
& $\mathrm{SD}=1.26$ & $\mathrm{SD}=1.21$ & 0.015 \\
Number Drinks in One Day & Mean $=3.83$ & Mean $=4.31$ & \\
& $\mathrm{SD}=1.20$ & $\mathrm{SD}=1.48$ & 0.012 \\
Most Drinks at Any One Time & $\mathrm{Mean}=7.07$ & Mean $=7.98$ & $\mathrm{SD}=2.36$ \\
\hline
\end{tabular}

Statistical Procedure $=$ ANOVA.

type of drink, however, all drinks were beer and many people drink more than one brand of these three common drinks (Table 4).

We then examined the between group differences before and after the intervention. In Table 5 we compare the groups on number of drinking days per week. In the control group the number of drinking days per week decreased from 2.8 to 1.4 (50\% reduction) compared with a reduction from 2.7 days to 0.85 days (68\%) for the intervention group. The between groups differences after controlling for weight, number of weeks gestation, and the pre-intervention between group differences was highly significant $p=0.008$ (Table 5). In the intervention group 18\% more women reduced the number of drinking days per week during pregnancy.

In Table 5 we summarized the between group differences on number of drinks per drinking day. The controls had a reduction from 4.3 drinks to 2.8 drinks (a 36\% reduction) compared with the intervention group with a reduction from 3.8 to 1.5 (a 61\% reduction) $\mathrm{p}=0.001$ (Table 5). In addition, a reduction in most drinks on any one occasion was observed. In the controls the reduction was from 7.9 drinks to 4.9 (38\% reduction) compared to the intervention group where the maximum number of drinks on an occasion went from 7.0 to 2.8 (61\% reduction). After controlling for between groups differences on weight, weeks gestation, and the between groups differences at baseline, the intervention was associated with highly significant reduction on most drinks on any one occasion $\mathrm{p}=.004$ (Table 5).

As a measure of the potential impact across the population we then examined the differences between groups on number of drinks per gestational week (drinking days per week x number of drinks per drinking day). We found that the controls had a $66 \%$ reduction in drinks per week compared to the intervention group where the number of drinks per week decreased by $87 \%$ after controlling for between group differences on weight, gestational week and differences at baseline (Figure 2).

We then examined how many women quit drinking. In the controls group 36.2\% (21 of 58) women quit drinking compared to $54.3 \%$ (88 of 162) in the intervention group, a between group difference of $18 \%$ (Chisquare 5.61; $\mathrm{p}=0.02)$ (Table 5). Alternatively, in the controls 31 of 58 (54.4\% did not modify their drinking patterns compared with 43 of 162) $(26.5 \%)$ in the intervention group (chi-square $=13.85 ; \mathrm{p}=0.0002)$. The proportion of women who drank 5 or more drinks on a drinking day decreased by $41.7 \%$ in the controls compared to an $81.8 \%$ decrease in the intervention group a between group difference of $40 \%$ (Chi-square $=9.83 ; \mathrm{p}=$ $0.002)$.

\section{Discussion}

After controlling for differences in maternal weight, gestational age, and between group differences at baseline we found significant improvements for the intervention group on quit rates, reductions in binge episodes and 
Table 4. Participant responses to the variable “what do you drink?”

\begin{tabular}{ccc}
\hline Drink & Intervention $[\mathrm{n}=162]$ & Controls [n $=58]$ \\
\hline Primus & $100(61.7 \%)$ & $21(36.2 \%)$ \\
Ngok & $49(30.2 \%)$ & $23(39.7 \%)$ \\
Mutzig Turbo & $13(8.0 \%)$ & $14(24.1 \%)$ \\
\hline
\end{tabular}

Chi-Square $=15.25, \mathrm{p}=0.001$.

Table 5. Exposure variables response to intervention.

\begin{tabular}{|c|c|c|c|c|}
\hline Group & Before Measure & After Measure & Change & $\begin{array}{c}\text { Significance } \\
\mathrm{p}=\end{array}$ \\
\hline \multicolumn{5}{|c|}{ Number of Days per Week Women Drink by group. } \\
\hline Controls & $\begin{array}{l}2.79 \text { Days } \\
\mathrm{SD}=1.21\end{array}$ & $\begin{array}{l}1.40 \text { Days } \\
\mathrm{SD}=1.36\end{array}$ & 1.39 [1.337] & \multirow{2}{*}{0.008} \\
\hline Intervention & $\begin{array}{l}2.72 \text { Days } \\
\mathrm{SD}=1.26\end{array}$ & $\begin{array}{l}0.85 \text { Days } \\
\text { SD }=1.11\end{array}$ & $1.87[.867]$ & \\
\hline \multicolumn{5}{|c|}{ Number of Drinks on a Drinking Day by Group } \\
\hline Controls & $\begin{array}{c}4.31 \text { Drinks } \\
\mathrm{SD}=1.48\end{array}$ & $\begin{array}{c}\text { 2.76 Drinks } \\
\mathrm{SD}=2.46\end{array}$ & 1.55 & \multirow{2}{*}{0.001} \\
\hline Intervention & $\begin{array}{c}3.83 \text { Drinks } \\
\mathrm{SD}=1.20\end{array}$ & $\begin{array}{c}1.47 \text { Drinks } \\
\mathrm{SD}=1.79\end{array}$ & 2.36 & \\
\hline \multicolumn{5}{|c|}{ Most Drinks on Any One Occasion by Group } \\
\hline Controls & $\begin{array}{c}\text { 7.98 Drinks } \\
\mathrm{SD}=2.36\end{array}$ & $\begin{array}{c}4.90 \text { Drinks } \\
\mathrm{SD}=4.39\end{array}$ & 3.08 & \multirow{2}{*}{0.004} \\
\hline Intervention & $\begin{array}{c}7.07 \text { Drinks } \\
\mathrm{SD}=2.38\end{array}$ & $\begin{array}{c}2.83 \text { Drinks } \\
\mathrm{SD}=3.41\end{array}$ & 4.24 & \\
\hline \multicolumn{5}{|c|}{ Proportion of Women who Quit Drinking } \\
\hline Controls & $58 / 58$ & $21 / 58$ & $36.2 \%$ & \multirow{2}{*}{$\begin{array}{l}\chi^{2} 5.61 \\
p=0.02\end{array}$} \\
\hline Intervention & $162 / 162$ & $88 / 162$ & $54.3 \%$ & \\
\hline
\end{tabular}

Statistical Procedure = ANCOVA (after controlling for weight, weeks pregnant and before days women drink in the week at baseline). $\chi^{2}=$ Chisquare.

reduction in cumulative exposure (drinking days $\mathrm{x}$ number of drinks per drinking day $\mathrm{x}$ gestational week). The intervention group had decreases in exposure for the key variables of drinking days per week (18\%), number of drinks per day (23\%), and most drinks at any one time (22\%). We also found an important decrease in exposure by number of drinks per gestational week by $22 \%$ compared to the controls indicating an important decrease in exposure in the last part of pregnancy. Evidence of decreased exposure was found for every exposure variable collected in this study.

In the Congo screening for PAE is efficient. One in five women screened report PAE [20]. The Congo now has effective strategies for identification of PAE that are cost effective and efficient. This study demonstrates that in addition to efficient identification strategies prenatal providers now have an effective intervention for use in prenatal care settings. One of every two women treated quit drinking. High rates of change on other exposure measures were also found. The intervention described here is low cost, easily implemented in a resource limited setting and is effective at both increasing the quit rate for women and reducing exposure for those who do not quit. The participant satisfaction appears high and the providers were supportive of the program. The intervention also has direct participant benefit. In the Congo the cost of a beer is about $\$ 1.50$ and a reduction in exposure during the last part of pregnancy would result in a saving well above the potential cost of the intervention. If the initial assessment could be implemented earlier in pregnancy (at 20 weeks) the reduction in exposure during the 


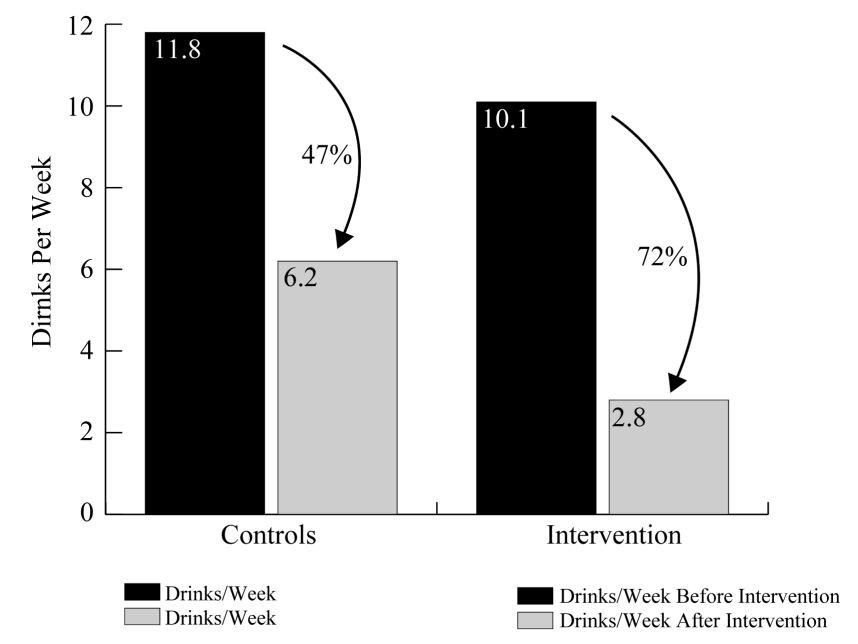

Figure 2. A bar graph comparing the mean number of drinks per week (number of drinking days per week x number of drinks per drinking day) for the control and intervention groups. After controlling for the initial differences between the groups the differences were significant $(F=16.09 ; p=0.001)$.

last 20 weeks of pregnancy would be about 50 drinks which would result in a cost savings of about $\$ 75.00$ per participant. If achievable this would represent a substantial cost saving for women in the Congo where the mean per-person annual health expenditure is $\$ 108$.

This study represents the first validation of a prenatal care intervention in the Congo that has a low burden on providers, has a statistically significant benefit for providers and participants. The benefit of the intervention for future pregnancies has not been assessed but may have the potential to reduce risk for exposure in subsequent pregnancies. Assessing the potential benefit for this group will require additional studies.

\section{Limitations}

Due to financial limitations we did not collect social or economic data on how the study participants may differ from women who did not attend prenatal care, women who attended other prenatal clinics who were not sampled and women from rural areas of the Congo. We do not have long term follow-up data to track how effective the intervention is over extended time periods especially after pregnancy. Another limitation that arose during data collection was the idea of what "one drink" is in Brazzaville. In the United States, one standard drink is defined as 12 ounces of beer, 5 ounces of wine, or 1.5 ounces of liquor or 14 grams of alcohol [27]. In Brazzaville many people consider drinking one bottle of beer to be "one drink," but bottles of beer vary in size and alcohol content. If the exposure reduction was calculated using 14 grams as the definition of a standard drink the actual reduction in exposure would be about 1.6 standard drinks for each "drink" as defined in Brazzaville. In subsequent studies, gathering specific dosimetry data on what type of alcohol is being consumed, the volume of the drink and the alcohol content of specific drinks will allow us to estimate exposure variables by grams of alcohol.

\section{Conclusions}

An important factor in reducing PAE is helping women become aware of the risk before pregnancy and again during pregnancy. At the time of the screening, the average woman in this group was entering her $3^{\text {rd }}$ trimester, suggesting high levels of cumulative exposure to alcohol and increased number of binge episodes during a pregnancy. This is a priority population for risk reduction strategies. Encouraging early prenatal care and screening would provide an opportunity for many more women to receive advice about risk and to have an exposure free second and third trimester. It is also important to recognize that effective screening during prenatal care and in-office advice about risk may also decrease exposure in subsequent pregnancies. This may provide an effective population based strategy to improve health and developmental outcomes for many women and children in Congo. 
PAE increases risk for maternal mortality, preterm birth, stillbirth, neonatal and infant mortality. These outcomes are important public health concerns in Congo and decreasing PAE may be an efficient strategy to reduce risk for these outcomes. We have now demonstrated an efficient strategy for detection of PAE and an office based intervention to reduce exposure in the Congo. Future studies will be needed to identify an expanded continuum of effective and affordable strategies to reduce exposure to alcohol prior to and during pregnancy.

\section{References}

[1] Lim, S.S., Vos, T., Flaxman, A.D., Danaei, G., Shibuya, K., Adair-Rohani, H., et al. (2012) A Comparative Risk Assessment of Burden of Disease and Injury Attributable to 67 Risk Factors and Risk Factor Clusters in 21 Regions, 1990-2010: A Systematic Analysis for the Global Burden of Disease Study 2010. Lancet, 380, 2224-60. http://dx.doi.org/10.1016/S0140-6736(12)61766-8

[2] Rehm, J., Mathers, C., Popova, S., Thavorncharoensap, M., Teerawattananon, Y. and Patra, J. (2009) Global Burden of Disease and Injury and Economic Cost Attributable to Alcohol Use and Alcohol-Use Disorders. Lancet, 373, 22232233.

[3] Parry, C.D.H. (2000) Alcohol Problems in Developing Countries: Challenges for the New Millennium. Suchtmed, 2, 216-220.

[4] Room, R., Selin, K.H. (2005) Problems from Women's and Men’s Drinking in Eight Developing Countries. In: Obot, I., Room, R., Eds., Alcohol, Gender and Drinking Problems: Perspectives from Low and Middle Income Countries, World Health Organization, Geneva, 209-220.

[5] Abel, E.L. (1997) Maternal Alcohol Consumption and Spontaneous Abortion. Alcohol and Alcoholism, 32, $211-219$. http://dx.doi.org/10.1093/oxfordjournals.alcalc.a008260

[6] Burd, L., Klug, M.G., Bueling, R., Martsolf, J., Olson, M. and Kerbeshian, J. (2008) Mortality rates in subjects with fetal alcohol spectrum disorders and their siblings. Birth Defects Research Part A: Clinical and Molecular Teratology, 82, 217-223.

[7] Burd, L. and Wilson, H. (2004) Fetal, Infant, and Child Mortality in a Context of Alcohol Use. American Journal of Medical Genetics Part C: Seminars in Medical Genetics, 127, 51-58.

[8] Cornman-Homonoff, J., Kuehn, D., Aros, S., Carter, T.C., Conley, M.R., Troendle, J., et al. (2011) Heavy Prenatal Alcohol Exposure and Risk of Stillbirth and Preterm Delivery. Journal of Maternal-Fetal and Neonatal Medicine, 25, 860-863.

[9] Kesmodel, U., Wisborg, K., Olsen, S.F., Henriksen, T.B., Secher, N.J. (2002) Moderate Alcohol Intake during Pregnancy and the Risk of Stillbirth and Death in the First Year of Life. American Journal of Epidemiology, 155, 305-312. http://dx.doi.org/10.1093/aje/155.4.305

[10] Li, Q., Fisher, W.W., Peng, C.Z., Williams, A.D., Burd, L. (2012) Fetal Alcohol Spectrum Disorders: A Population Based Study of Premature Mortality Rates in the Mothers. Maternal and Child Health Journal, 16, 1332-1337. http://dx.doi.org/10.1007/s10995-011-0844-3

[11] Croxford, J. and Viljoen, D. (1999) Alcohol Consumption by Pregnant Women in the Western Cape. South African Medical Journal, 89, 962-965.

[12] May, P.A., Gossage, J.P., Kalberg, W.O., Robinson, L.K., Buckley, D., Manning, M., et al. (2009) Prevalence and Epidemiologic Characteristics of FASD from Various Research Methods with an Emphasis on Recent In-School Studies. Developmental Disabilities Research Reviews, 15, 176-192. http://dx.doi.org/10.1002/ddrr.68

[13] Chaibva, C.N., Ehlers, V.J., Roos, J.H. (2011) Audits of Adolescent Prenatal Care Rendered in Bulawayo, Zimbabwe. Midwifery, 27, e201-207. http://dx.doi.org/10.1016/j.midw.2010.07.009

[14] Medhin, G., Hanlon, C., Dewey, M., Alem, A., Tesfaye, F., Worku, B., et al. (2010) Prevalence and Predictors of Undernutrition among Infants Aged Six and Twelve Months in Butajira, Ethiopia: The P-MaMiE Birth Cohort. BMC Public Health, 10, 27.

[15] World Health Organization (2011) World Health Statistics 2011. http://www.who.int/whosis/whostat/EN WHS2011 Full.pdf

[16] U.S. Department of State (2012) Background Note: Republic of the Congo. http://www.state.gov/r/pa/ei/bgn/2825.htm

[17] Partnership for Maternal, Newborn \& Child Health (2012) Born Too Soon: The Global Action Report on Preterm Birth. http://www.who.int/pmnch/media/news/2012/preterm_birth_report/en/index4.html

[18] World Health Organization. Trends in Maternal Mortality 1990-2008. Geneva: World Health Organization; 2010.

[19] Central Intelligence Agency (2012) The World Factbook 2012: Country Comparison: Infant Mortality Rate. 
https://www.cia.gov/library/publications/the-world-factbook/rankorder/2091rank.html

[20] Williams, A.D., Nkombo, Y., Nkodia, G., Leonardson, G. and Burd, L. (2013) Prenatal Alcohol Exposure in the Republic of the Congo: Prevalence and Screening Strategies. Birth Defects Research Part A: Clinical and Molecular Teratology, 97, 489-496. http://dx.doi.org/10.1002/bdra.23127

[21] Williams, A.D., Nkombo, Y., Nkodia, G., Leonardson, G. and Burd, L. (2014) Prevalence of Smoking during Pregnancy in the Republic of the Congo: Maternal Smoking Is Associated with Increased Prenatal Alcohol Exposure. International Journal of Alcohol and Drug Research, in Press.

[22] Namagembe, I., Jackson, L.W., Zullo, M.D., Frank, S.H., Byamugisha, J.K. and Sethi, A.K. (2010) Consumption of Alcoholic Beverages among Pregnant Urban Ugandan Women. Maternal and Child Health Journal, 14, 492-500. http://dx.doi.org/10.1007/s10995-009-0500-3

[23] Tandu-Umba, B., Mbangama, M.A., Mbungu, M.R. (2011) Effect of Maternal Alcohol Consumption on Gestational Diabetes Detection and Mother-Infant's Outcomes in Kinshasa, DR Congo. Open Journal of Obstetrics and Gynecology, 1, 208-212. http://dx.doi.org/10.4236/ojog.2011.14040

[24] Population Reference Bureau [Internet] Washington DC (2012) Birth Rate (Annual Number of Births per 1,000 Total Population). http://www.prb.org/DataFinder/Topic/Rankings.aspx?ind=3

[25] Burd, L.J., Cotsonas-Hassler, T.M., Martsolf, J. and Kerbeshian, J. (2003) Recognition and Management of Fetal Alcohol Syndrome. Neurotoxicology and Teratology, 25, 681-688. http://dx.doi.org/10.1016/j.ntt.2003.07.020

[26] Burd, L.J., Klug, M.G., Martsolf, J.T., Martsolf, C., Deal, E. and Kerbeshian, J. (2006) A Staged Screening Strategy for Prenatal Alcohol Exposure and Maternal Risk Stratification. Journal of the Royal Society of Health, 126, 86-94.

[27] National Institute on Alcohol Abuse and Alcoholism (2007) What’s a Standard Drink? http://pubs.niaaa.nih.gov/publications/practitioner/pocketguide/pocket_guide2.htm 